\title{
Normal human chromosomes have long G-rich telomeric overhangs at one end
}

\author{
Woodring E. Wright, ${ }^{1,3}$ Valerie M. Tesmer, ${ }^{1}$ Kenneth E. Huffman, ${ }^{2}$ Stephen D. Levene, ${ }^{2}$ and \\ Jerry W. Shay ${ }^{1}$ \\ ${ }^{1}$ Department of Cell Biology and N euroscience, The University of Texas Southwestern Medical Center, Dallas, Texas \\ 75235-9039 USA; ${ }^{2}$ Program in Molecular and Cell Biology, University of Texas at Dallas, Richardson, Texas 75083 USA
}

\begin{abstract}
Telomeres protect the ends of linear chromosomes from degradation and abnomal recombination events, and in vertebrates may be important in cellular senescence and cancer. However, very little is known about the structure of human telomeres. In this report we purify telomeres and analyze their termini. We show that following replication the daughter telomeres have different terminal overhangs in normal diploid telomerase-negative human fibroblasts. Electron microscopy of those telomeres that have long overhangs yields $\mathbf{2 0 0} \pm \mathbf{7 5}$ nucleotides of singlestranded DNA. This overhang is four times greater than the amount of telomere shortening per division found in these cells. These results are consistent with models of telomere replication in which leading-strand synthesis generates a blunt end while lagging-strand synthesis produces a long G-rich 3' overhang, and suggest that variations in lagging-strand synthesis may regulate the rate of telomere shortening in normal diploid human cells. Our results do not exclude the possibility that nuclease processing events following leading strand synthesis result in short overhangs on one end.
\end{abstract}

[Key Words: Telomeres; DNA replication; chromosome structure; cellular senescence; aging]

Received July 31, 1997; revised version accepted September 5, 1997.

Telomeres are the specialized ends of linear chromosomes that are involved in a variety of functions, including mei otic chromosome segregation, chromatin silencing, and protecting the ends of the chromosomes from degradation or end-to-end fusion (for review, see Blackburn 1994; Zakian 1995; Greider 1996). In most organisms, tel omeres are composed of repetitive sequences in which the strand with its $3^{\prime}$ end at the terminus is G-rich and may extend beyond the DNA duplex to form a single-stranded G-rich overhang. In humans, telomeres contain up to several thousand repeats of the sequence TTAGGG (M oyzis et al . 1988; Cross et al. 1989). Because of the requirement for an RNA primer, DNA polymerases are unable to replicate the extreme $3^{\prime}$ end of a parental DNA strand (Watson 1972; Olovnikov 1973) and, in the absence of compensatory mechanisms, telomeres shorten with each cell division. The ribonucleoprotein telomerase provides such a compensatory mechanism. Telomerase contains reverse transcriptase motifs (Lingner et al . 1997), and using its RNA component as a template (Greider and Blackburn 1989), it can add repetitive sequences to the $3^{\prime}$ end of the chromosomes. Eliminating the RN A component of tel omerase prevents this activity and results in telomere shortening in organisms ranging from yeast to humans (Singer and Gottschling 1994; Blasco et al. 1995; Feng et al. 1995). Telomerase activity can be detected in the vertebrate testis (Prowse and Greider 1995; Wright et al. 1996), and telomere length is maintained in the germ line (Cooke and Smith 1986; Hastie et al. 1990; de Lange et al. 1990). However, telomerase activity is repressed in most human tissues during development (Wright et al. 1996) and progressive telomere shortening is then observed (Hastie et al. 1990; Lindsey et al. 1991). This shortening has been proposed to serve as a mitotic clock that counts cell divisions and ultimately results in cellular senescence (de Lange et al. 1990; Greider 1990; Harley et al. 1990; Harley 1991; Wright and Shay 1995). The ability to maintain tel omere length may be important in cancer formation, as approximately $85 \%$ of all human primary tumors express tel omerase activity (for review, see Shay and Bachetti 1997).

The detailed structure of telomeric ends has been de termined in hypotrichous ciliates such as Oxytricha nova, where a double-stranded region of $28 \mathrm{bp}$ of TTTTGGGG repeats is followed by 14 nucleotides of a G-rich single-stranded overhang (Klobutcher et al. 1981). In Saccharomyces cerevisiae, although a longer singlestranded region can be transiently observed in late $S$ phase, during most of the cell cycle any G-rich overhangs that are present are shorter than a 30-nucleotide detection limit (Wellinger et al. 1993). The loss of $\sim 5$ bp per division in yeast lacking telomerase RNA is consistent with a model in which both ends of the yeast telomere have an 10-nucleotide G-rich overhang (Zakian 1995). Recent models for the action of telomerase have empha- 
sized the need for processing of the blunt end generated by leading strand synthesis so that it can be a substrate for telomerase, with subsequent processing events generating chromosomes with symmetrical telomeres containing short G-rich overhangs (Lingner et al. 1995; Lingner and Cech 1996; Wellinger et al. 1993, 1996). These models have a working assumption that there is a primase activity that can position an RNA primer at the extreme $3^{\prime}$ end of the chromosome. Such a primase activity has been found in O. nova (Zahler and Prescott 1988).

In contrast to yeast telomeres which lose only a few base pairs per di vision in the absence of tel omerase, telomeres from normal dipl oid human cells have been found to shorten at rates varying between 40 and 200 bp per division (Harley et al. 1990; Counter et al. 1992; Shay et al. 1993; Vaziri et al. 1993). There are at least three hypotheses to explain the much greater losses in human cells. Exposure to oxygen levels $\mathbf{3} 20 \%$ causes premature senescence in human fibroblasts, and it has been proposed that unrepaired oxidative damage causes the onestep loss of long stretches of telomeric repeats (von Zglinicki et al. 1995). This hypothesis predicts that the rate of loss of telomeric DNA under normoxic conditions would represent the average between slow rates of shortening on most chromosomes and rapid losses on some damaged chromosomes. A second hypothesis is that processing events involving the nucleolytic degradation of one or both strands would cause increased rates of shortening in human telomeres ( $M$ akarov et al. 1997). There is good evi dence for a variety of processing mechanisms at telomeres. Different mutations in the yeast single-stranded telomeric binding protein cdc13p can cause the massive nucleolytic degradation of the $\mathrm{C}$-rich strand (Garvik et al. 1995) or a failure of yeast tel omerase to maintain telomere length ( $N$ ugent et al. 1996). The appearance of transient $\geqslant 30$-nucleotide overhangs on both ends of yeast chromosomes does not require yeast telomerase (Wellinger et al. 1996), and a nuclease able to digest $\mathrm{G} 4$ tetrastrand structures has been identified (Liu and Gilbert 1994). These observations suggest that specific nucleolytic processing of tel omeres occurs in yeast. Nucleolytic processing is also seen in ciliates. The Grich strand added by tel omerase to the newly fragmented macronuclear DNA in hypotrichous ciliates is initially longer than in mature telomeres (Roth and Prescott 1985; Vermeesch and Price 1994), and the preferential pause site used by telomerase in vitro is not found at the end of ciliate telomeres synthesized in vivo (Klobutcher et al. 1981; Henderson et al. 1988; Shippen-Lentz and Blackburn 1989; Greider 1991). A third hypothesis is that human cells lack the ability to position the final RNA priming event at the very end of the chromosome. RN A priming events are thought to occur about every 100-600 bp during lagging strand synthesis in mammals (Anderson and DePamphilis 1979; DePamphi lis 1993; Waga and Stillman 1994). This is roughly consistent with the rates of telomereshortening of 40-200 bp per cell division that has been observed in cultured human cells. The length of the single-stranded G-rich overhang might thus repre- sent the distance between the last priming event during lagging strand synthesis and the end of the chromosome.

As a first step in distinguishing between these models, we have devel oped techniques for purifying human telomeres and examining their structure. Our results demonstrate that the telomeres generated by leading versus lagging strand DNA synthesis are different and suggest that each chromosome has one tel omere with a long Grich overhang and one that is either blunt or has a short G-rich overhang. We provide the first direct el ectron microscopic measurement of the single-stranded region in telomeres from normal diploid human cells and find a $200 \pm 75$-nucleotide overhang. The rate of telomere shortening of $50 \mathrm{bp}$ per division in these cells is consistent with model s in which shortening results from overhangs produced by lagging strand synthesis. Our results do not support models of telomere shortening in which the primary mechanism is either oxidative damage or nucleolytic processing.

\section{Results}

Purification of human telomeres

Human telomeres were purified based on the ability of bi otinylated ol igonucleotides complementary to the Grich telomeric repeat to anneal to the G-rich overhang in otherwise doublestranded DNA (Shay et al. 1994). Following annealing, DNA/oligonucleotide complexes were bound to streptavidin-coated magnetic beads and washed, and the telomeres were eluted and analyzed on agarose gels. Figure $1 \mathrm{~A}$ demonstrates the sequence specificity of this purification. Although the tel omeres in human placental DNA can be retrieved using biotinylated ol igonucleotides containing four or six $\mathrm{C}$-rich telomeric repeats $\left(C T R_{4}\right.$ and $\left.C T R_{6}\right)$, neither six copies of the G-rich repeat $\left(\mathrm{GTR}_{6}\right)$ nor a non-tel omeric oligonucleotide (Cla$\mathrm{Hin}$ ) were able to bind telomeres. The failure of the Grich repeat to purify telomeres suggests that the binding of telomeres by the $\mathrm{C}$-rich oligonucleotide is not due to strand invasion or gaps in the double-stranded DN A but, rather, is dependent on the presence of the G-rich $3^{\prime}$ overhang. Digestion of the DNA with exonuclease I re sulted in a fourfold reduction in recovery and confirmed that most of this purification required a single-stranded overhang (Fig. 1B). We suspect that the presence of noncanonical structures such as G-quartets involving some of the overhangs may block exonuclease I activity, leaving some exonuclease-resistant single-stranded regions intact and thus available for hybridization to the biotinylated C-rich oligonucleotides. The minimal overhang that could be recovered with this technique was determined using an artificial telomere constructed by ligating a linearized 5-kbp plasmid to short double-stranded fragments containing variable numbers of TTAGGG repeats as single-stranded $3^{\prime}$ extensions. Overhangs containing as few as 12 nucleotides could be recovered (Fig. 1C).

The average efficiency of purification of telomeres [bound $\div$ (bound +unbound)] using DNA from normal 


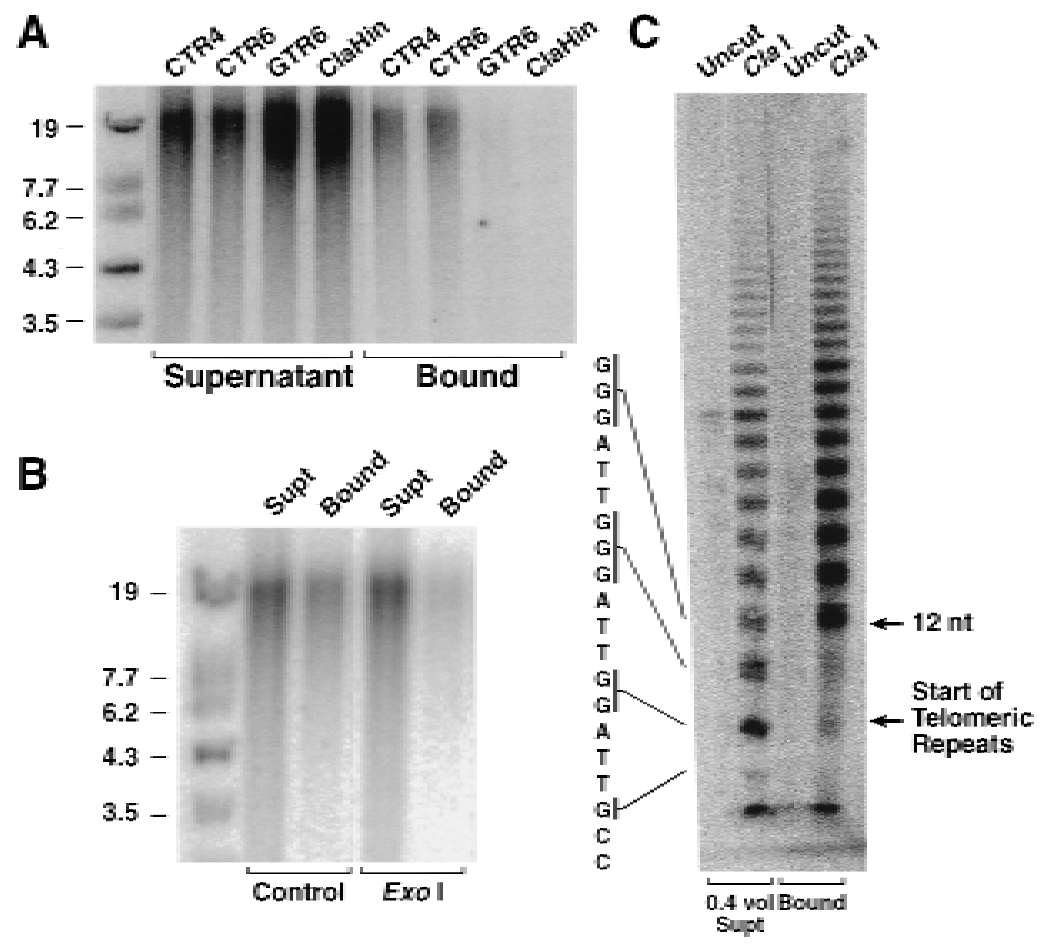

Figure 1. Purification of telomeres. (A) Sequence specificity of the purification of telomeres. Hinfldigested human placental DNA was annealed to various biotinylated oligonucleotides, and telomere/oligonucleotide complexes were captured with streptavidin-coated magnetic beads. The DN A remaining in the supernatant vs. that bound to the beads was then analyzed on agarose gels and probed with a ${ }^{32} \mathrm{P}$-labeled (TTAGGG) 4 oligonucleotide. $C T R_{4}$ and $C T R_{6}$ contain four and six copies of the $C$-rich terminal repeat (CCCTAA), $\mathrm{GTR}_{6}$ contains six copies of the G-rich terminal repeat (TTAGGG), and ClaHin is a nontelomeric biotinylated oligonucleotide. Only the C-rich oligonucleotides complementary to the G-rich telomeric overhang were able to retrieve the doublestranded placental telomeres. (B) Purification requires single-stranded overhangs. Treatment of the DNA with the single-stranded exonuclease Exo 1 $(1 \mathrm{U} / \mu \mathrm{g})$ largely abolished the ability to retrieve tel omeres. N oncanonical G structures (Henderson 1995; Kipling 1995) may make a small fraction of the overhangs resistant to complete digestion. (C) Purification requires $\geqslant 12$ bases of overhang. A 5kbp artificial telomere containing single-stranded G-rich overhangs of variable lengths was annealed to a biotinylated C-rich oligonucleotide and purified using streptavidin-coated magnetic beads. The material bound to the magnetic beads or remaining in the supernatant is large and does not enter a denaturing polyacrylamide gel (uncut lanes). The radioactive tel omeric repeats were rel eased by digestion with an enzyme that cuts the plasmid just before the start of the telomeric repeats (Clal). Sequences containing as few as 12 nucleotides of G-rich overhangs can be recovered even if they are part of a 5-kbp-long artificial telomere.

diploid BJ human foreskin fibroblasts was $33 \% \pm 15 \%$ (18 experiments). If fresh biotinylated C-rich oligonucleotide was annealed to the unbound fraction, an additional $10 \% \pm 5 \%$ (8 experiments) of the original telomeres could be recovered. Only $2 \% \pm 2 \%$ (7 experiments) of the original tel omeres were bound fol lowing a third cycle of purification. The total recovery following three cycles of purification $(33 \%+10 \%+2 \%=45 \%)$ suggested that only half of the telomeres might have long G-rich overhangs.

\section{Daughter telomeres do not have similar overhangs}

The ability to purify tel omeres containing overhangs allowed us to test the hypothesis that the G-rich overhang results from the gap between the last Okazaki priming event of lagging strand synthesis and the end of the chromosome. This model predicts that a blunt end is produced by leading strand synthesis, and thus the newly synthesized G-rich daughter strand would be present on a blunt-ended telomere and would not be purified by techniques that require overhangs (Fig. 2A). The daughter strands in normal diploid BJ human foreskin fibrobl asts were labeled by growing cells for zero, one, or four divisions in the presence of 5-bromodeoxyuridine (BrdU). This generated unsubstituted (Thy:Thy), hemisubsituted (Thy:BrdU), and fully substituted (BrdU :BrdU) DN A. The telomeres with long overhangs were then purified, mel ted, and the BrdU-contai ning strands recovered using
anti-BrdU antibodies. Figure 2B demonstrates that Crich and G-rich daughter strands were not uniformly distributed among tel omeres that have long overhangs. Unsubstituted tel omeres (Thy:Thy, containing only thymidine in both strands after zero divisions in BrdU) were not retrieved by the anti-BrdU antibodies, whereas both $\mathrm{C}$-rich and G-rich strands were recovered with equal efficiency from tel omeres that had incorporated BrdU into both strands (BrdU:BrdU, after four divisions in BrdU). M ostly C-rich strands were bound by anti-BrdU antibodies in the hemisubstituted telomeres with long overhangs (Thy:BrdU, containing BrdU in only the daughter strand after one division in BrdU), indicating that the G-rich strand was the parental strand (and thus lacked BrdU after one round of DNA synthesis).

Table 1 presents the results from six experiments involving nine different samples of hemisubstituted DN A. On average, $5.4( \pm 2.8)$ times as much C-rich as G-rich strands were bound by the anti-BrdU antibodies. This bias for BrdU incorporation into the C-strand in telomeres with long overhangs shows that these telomeres represent a population from one and not both ends of the chromosome.

\section{Electron microscopic examination of telomeric overhangs}

We measured the length of the telomeric overhang with electron microscopy by visualizing bacteriophage T4 

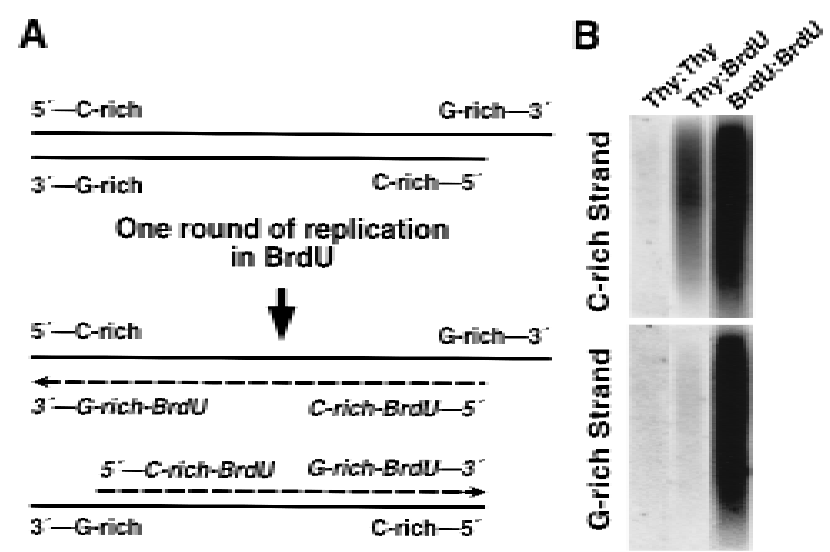

Figure 2. Telomeres with long overhangs contain newly synthesized C-rich daughter strands. (A) Schematic model for telomere replication. This model postulates that lagging-strand synthesis leaves a $3^{\prime}$ overhang of the parental G-rich strand. Following one round of replication in BrdU, labeled G-rich strands are present in blunt-ended telomeres, whereas labeled C-rich strands are present in telomeres that have overhangs. (B) Retrieval of BrdU-labeled daughter strands. Telomeres from BJ fibroblasts, in which both strands contained thymidine (Thy:Thy), only one strand contained BrdU after a single round of replication (Thy:BrdU), or both strands contained BrdU after four rounds of replication (BrdU:BrdU), were purified using biotinylated $\mathrm{C}$-rich oligonucleotides, melted, and then precipitated with anti-BrdU antibodies. The antibody-bound DN A was then rel eased by boiling in SDS, analyzed on agarose gels, and probed with oligonucleotides specific for each strand. The amount of purified telomeres used in each sample was not identical, as the efficiency of magnetic bead purification varied between experiments. The exposure of each lane has been adjusted to represent equivalent amounts of input telomeres (antibody bound +unbound for each strand). The newly synthesized (BrdU-containing) strand on those telomeres that contained long overhangs was the $\mathrm{C}$-rich and not the $\mathrm{G}$-rich strand.

gene 32 protein (gp 32) bound to single-stranded DN A in tungsten-shadowed preparations. Size standards for the quantitation of the length of single-stranded telomeric overhangs were prepared that contained cloned telomeric repeats as either terminal overhangs or internal single-stranded gaps. Figure $3 \mathrm{~A}$ shows an example of the images obtained with an internal 450-nucleotide gap, and Figure 3B shows the linear relationship between the length of the gp32-coated region and the number of nucleotides for both internal and terminal singlestranded regions. Tracings of the protein-coated region yiel ded a val ue of $0.42 \pm 0.02 \mathrm{~nm} /$ nucleotide, very close to previously published reports of $0.46 \mathrm{~nm} /$ nucleotide (Delius et al. 1972; Wu and Davidson 1975). Analysis of overhang-containing BJ fibroblast tel omeres coated with T 4 gp32 (Fig. 3C) yiel ded an average single-stranded overhang length of $200 \pm 75$ nucl eotides (Fig. 3D). This is an order of magnitude greater than that found in organisms such as ciliates and yeast (Klobutcher et al. 1981; Wellinger et al. 1993) and consistent with recent estimates for human telomeres based on indirect biochemical tech- niques ( $M$ akarov et al. 1997; M cEllingott and Wellinger 1997).

\section{Tel omere shortening in fibroblasts}

Models of chromosome replication in the absence of telomerase in which only one telomere contains a long G-rich overhang predict that the size of the overhang should be four times the amount of shortening per doubling (Fig. 4, step 1). BJ fibroblast telomeres shorten by
A

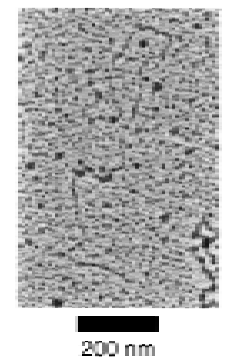

c
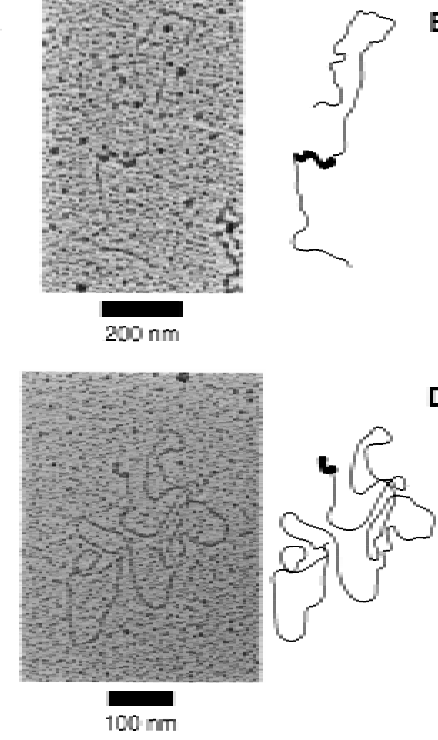

B

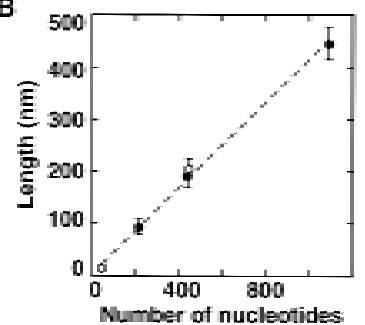

D

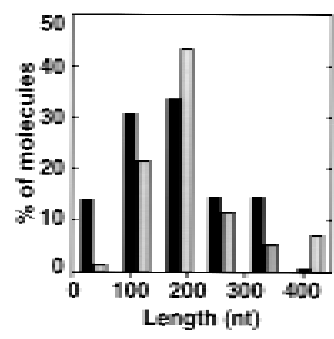

Figure 3. T4 gp32 decoration of single-stranded DN A and telomeric overhangs. (A) The singlestranded region of linearized plasmid DNA containing a 450-nucleotide gap of singlestranded tel omeric repeats was decorated with the single-strand binding T4 gp32. Initial magnification, 100,000× (B) Linear relationship between size standards and measured lengths. Different lengths of singlestranded gaps $(\mathbf{0})$ or overhangs $(\mathrm{O})$ coated with gp32 were examined. The 48- and 450-nucleotide single-stranded regions contained G-rich tel omeric repeats; the 200- and 1000-nucleotide gaps contained plasmid sequences. Except for the 48-nucleotide overhang, 40-70 molecules of each type were examined. It was difficult to distinguish the very short decorated region from background for the 48-nucleotide overhang sample, and we consider 50 nucl eotides of overhang to be the limit of detection for this technique. Error bars indicate 1 standard deviation (S.D.). (C) Purified BJ fibroblast telomere decorated with gp32. Initial magnification, 25,000x (D) Histogram of the length of the gp32-decorated regions of purified telomeres from BJ fibroblast DN A. A total of 108 and 69 molecules from population doubling level (PDL) 20 (solid bar) and 87 (shaded bar) were examined. Between $70 \%$ and $80 \%$ of the molecules purified on the basis of having G-rich overhangs had one decorated end. The remaining undecorated molecules may represent fragments of broken tel omeres. $N$ one of the tel omeres was decorated at both ends. Average overhang lengths ( \pm S.D.) were $157 \pm 69$ nucleotides for PDL20 and $226 \pm 88$ nucleotides for PDL87 fibroblasts. A higher background of free T4 gp32 in the PDL87 preparation may have compromised our ability to detect the shortest overhangs in that sample. 
50 bp per division in culture (Fig. 5), which is onefourth of the 200-nucleotide overhang we observed. M odels for telomere shortening in which nuclease processing generates symmetrical overhangs at both ends of the chromosome predict that the size of the overhang should be twice the rate of shortening per division (Fig. 4, step 2), which is not supported by our data.

\section{Discussion}

To our knowledge, the only rigorous evidence for symmetrical overhangs on both ends of a chromosome comes from studies of hypotrichous ciliates, in which the small and well-defined telomere length has permitted the direct sequencing of both telomeric strands of
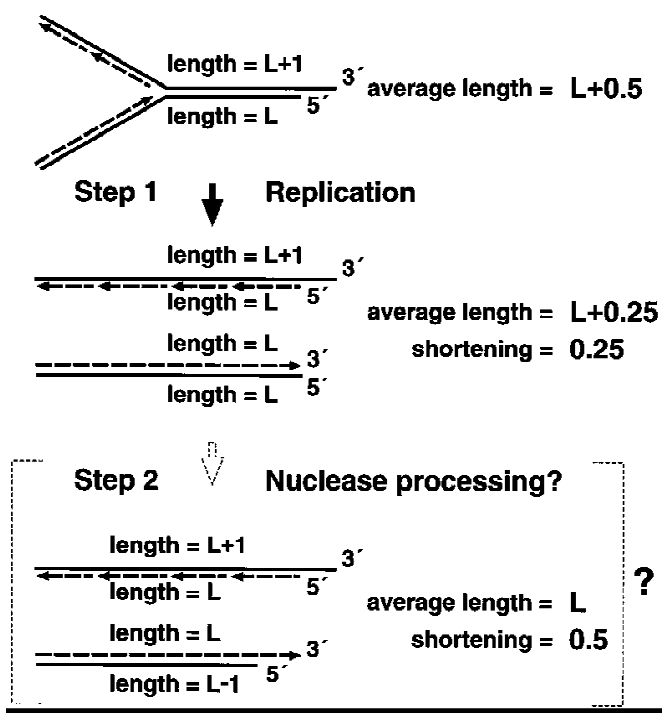

Figure 4. Tel omere size changes after chromosome replication in the absence of telomerase. A replication fork is shown proceeding into a tel omere of length $L$ with a 3' G-rich overhang 1 unit long. The size of the telomere before replication is the average of the two strands, which is $[(L+1)+L] \div 2=L+0.5$ units. Lagging strand synthesis is illustrated as a series of discrete Okazaki fragments that would be joined together to form a continuous strand. Following replication, lagging strand synthesis would leave a long 3' overhang; leading strand synthesis would generate a blunt end. After replication is complete (step 1) the average size of the four strands would be $[(\mathrm{L}+1)+\mathrm{L}+\mathrm{L}+\mathrm{L}] \div 4=\mathrm{L}+0.25$ units. The net shortening after replication would be $(L+0.5)-(L+0.25)=0.25$, implying that the rate of telomere shortening should be one-quarter of the length of the G-rich overhang. A recent model (Makarov et al. 1997) has been postulated, in which extensive nuclease processing produces symmetrical long overhangs (step 2). If this were to occur, the average size of the four strands would be $[(\mathrm{L}+1)+\mathrm{L}+\mathrm{L}+(\mathrm{L}-1)] \div 4=\mathrm{L}$. The net shortening after replication and processing would thus be $(L+0.5)-L=0.5$, suggesting that the rate of tel omere shortening in the absence of tel omerase should be one-half the length of the G-rich overhang. Our data indicate that the rate of shortening ( $50 \mathrm{bp} /$ division) is one quarter the length of the overhang ( $200 \pm 75$ nucleotides) in BJ fibroblasts.
A

\section{Population Doubling}

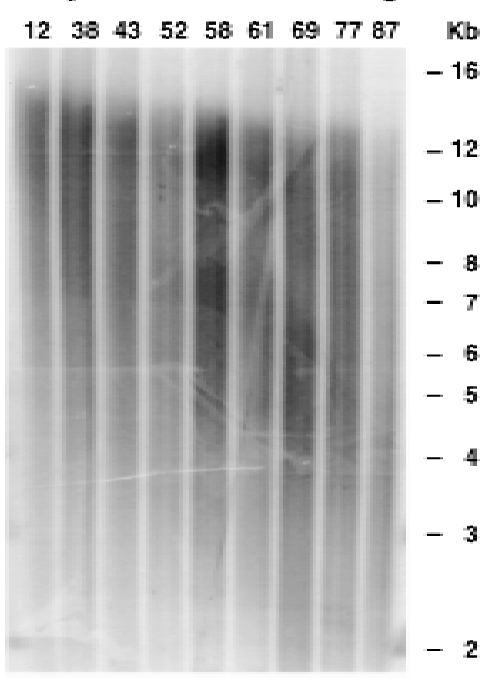

B

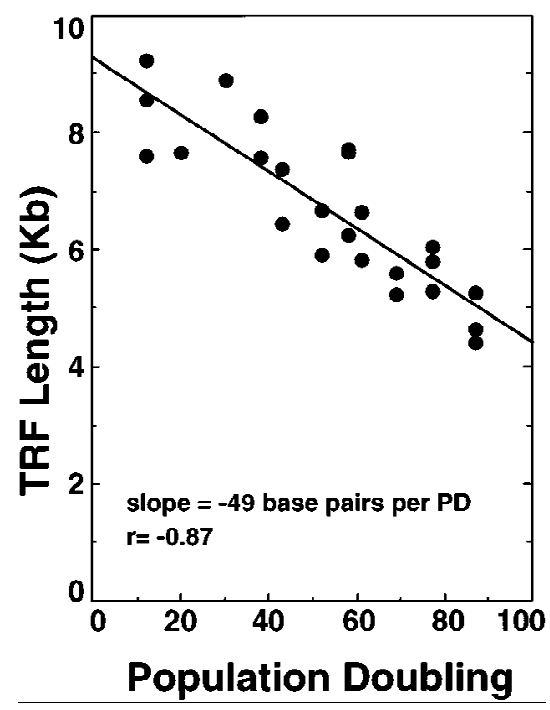

Figure 5. Telomere shortening in BJ fibroblasts. (A) Terminal restriction fragment (TRF) gel of DNA from BJ foreskin fibroblasts at different mean population doubling levels. (B) Rate of telomere shortening. Data from three different TRF gels using DNA prepared from two different lifespan studies are shown. The average rate of shortening was $49 \mathrm{bp} /$ population doubling.

end-labeled total DNA (Klobutcher et al. 1981). The larger size and variable length of telomeres in other organisms has prevented a comparable analysis of their telomeres. The data in yeast showing the temporary circularization of linear plasmids owing to the presence of transient overhangs demonstrates that overhangs might be present on both ends of some of the chromosomes some of the time but does not directly address whether or not the overhangs are symmetrical or uniform. Our data show that the presence of long overhangs on only 
one end of the chromosome in normal human fibroblasts differs from the symmetrical ends found in the hypotrichous ciliates.

Anti-BrdU antibodies recognized the C-rich but not the G-rich strand in telomeres purified based on their long overhangs from cells after a single cycle of DNA replication. This demonstrates that these tel omeres contain a daughter strand synthesized from the G-rich telomeric template. Y east origins of replication are internal to the tel omere (Raghuraman et al . 1997). Assuming that the origins for telomere replication are also internal in vertebrates, our results show that long overhangs are present in telomeres that are produced by lagging-strand synthesis.

The $200 \pm 75$-nucleotide overhang we observed in $\mathrm{BJ}$ fibroblasts is sufficient to fully explain the rate of telomere shortening of 50 bp per division found in these cells using calculations based on models in which the telomere at one end of the chromosome is blunt and the one at the other end has a long G-rich overhang. These observations do not support the hypothesis that the rate of shortening represents the average of a few telomeres, which suffer oxi dative damage and l ose kil obases of telomeric sequences, and the majority of telomeres, which I ose only very few nucleotides because of short unreplicated overhangs (von Zglinicki et al. 1995).

The biotinylated $\mathrm{C}$-rich oliogonucleotides we have used are unable to bind singl e-stranded G-rich overhangs of less than 12 nucleotides with sufficient stability to recover artificial telomeres $5 \mathrm{kbp}$ long. We are thus unable to determine whether the telomeres resistant to purification are blunt ended or have very short overhangs. The presence of short overhangs would be consistent with the concept that proteins recognizing a singlestranded overhang might be required to cap the telomeres and prevent them from being degraded (Gottschling and Cech 1984; Gottschling and Zakian 1986). The BrdU labeling data does not exclude the possibility that leading and lagging strands might be processed differently, so that only one end is packaged into a G-quartet-like structure that is stable to the DN A isol ation procedure and resistant to hybridization to the biotinylated C-rich oligonucleotides. Under this circumstance, one end might have a long but inaccessible G-rich overhang. However, the relationship between the measured length of the overhang and the observed rate of shortening (Figs. 3-5) argues against long overhangs on both daughter telomeres.

Makarov et al. (1997) recently reported that human telomeres contain long $\mathrm{G}$ tails at both ends of the chromosome. The strand-repl acement technique (PEN T) that these workers used to detect G-rich overhangs does not distinguish between long and short overhangs, and thus their conclusion that human cells contain symmetrical overhangs is not justified. In addition, their claim that $85 \%$ of human tel omeres have G-rich overhangs may be in error. This assertion is entirely dependent on Phosphorlmager scans of the relative intensities of three bands: full-length $C$-rich strands $\left(C_{0}\right)$, newly synthesized replacement strands primed from the G-rich overhang
$\left(\mathrm{C}_{\mathrm{s}}\right)$, and the original $\mathrm{C}$-strand being trimmed back as replacement synthesis progresses $\left(C_{t}\right)$. Their quantitation showed that the intensity of $C_{0}$ was $\sim 15 \%$ of the sum of $\mathrm{C}_{\mathrm{s}}+\mathrm{C}_{\mathrm{t}}$, and they thus concluded that $85 \%$ of the telomeres had overhangs. However, their data (Fig. 5 in Makarov et al. 1997) indicate that they underestimated the amount of Iarge DNA present. For example, even assuming that a $12.5-\mathrm{kb}$ telomere digested with $\mathrm{Hinfl}$ contains $2.5 \mathrm{~kb}$ of subtel omeric DN A that lacks repeats (Levy et al. 1992), the number of telomeric repeats in a 12.5-kb $\mathrm{C}_{\mathrm{o}}$ and a 10-kb $\mathrm{C}_{\mathrm{t}}$ strand should be approximately three times the number in a $2.5-\mathrm{kb} \mathrm{C}_{\mathrm{s}}$ strand. Rather than finding a threefol d greater signal intensity in the large DN A probed with the G-rich telomeric repeat, their data show an approximately equal intensity of the small $2.5-\mathrm{kb} \mathrm{C}_{\mathrm{s}}$ strand. Their quantitation of the fraction of telomeres that lacked available overhangs and were resistant to replacement synthesis (the fraction that was the $C_{0}$ strand) could thus be off by a factor of three or more. We suspect that these results may be explained by an inefficient transfer of large DN A to the membrane in the vacuum blotting procedure they employed.

Much recent evidence implicates single-strand nucle ases in telomere processing in telomerase-expressing model organisms (Wellinger et al. 1993, 1996; Garvik et al. 1995; Linger et al. 1995; N ugent et al. 1996), raising the possibility that human telomeres might be processed to have uniform G-rich overhangs. The data in the present report provide direct evidence that this is not the case in a telomerase-negative cell strain. Leading and lagging strand synthesis results in distinct telomeric structures in normal diploid human fibroblasts. Our results do not formally exclude the possibility that asymmetric overhangs could be generated by nuclease activity. We consider this unlikely, as an additional mechanism to restrict the digestion to the newly synthesized C-rich strand and not the parental C-rich strand would be required.

The presence of telomerase activity in most human tumors has generated much excitement concerning the potential efficacy of anti-telomerase therapies for the treatment of cancer. Understanding what regulates the rate of telomere shortening and how to manipulate it may provide the tools to increase the effectiveness of telomerase inhibitors in preventing the regrowth of tumor cells.

\section{Materials and methods}

Purification of telomeres

Double-stranded genomic DN A was digested overnight in 0.25 $\mathrm{U} / \mu \mathrm{g}$ of $\mathrm{Hinfl}$ to free the telomeric repeats from most of the subtel omeric sequences. In a typical experiment, $30 \mu \mathrm{g}$ of DN A in a final volume of $30 \mu \mathrm{l}$ was then adjusted to $1 \times \mathrm{SSC} / 1 \%$ Triton X-100, mixed with 1 pmole of a biotinylated ol igonucleotide, anneal ed for $15 \mathrm{~min}$ each at $65^{\circ} \mathrm{C}, 55^{\circ} \mathrm{C}, 45^{\circ} \mathrm{C}, 35^{\circ} \mathrm{C}$, and room temperature, and combined with $3 \mu \mathrm{l}$ of washed streptavidin-coated magnetic beads ( $10 \mathrm{mg} / \mathrm{ml}$ suspension, Dynal Inc.) that had been preincubated for at least $1 \mathrm{hr}$ in $5 \times$ Denhardt's solution. The DNA-bead suspension was rotated end over end 
at $2 \mathrm{rpm}$ and $4^{\circ} \mathrm{C}$ overnight. The magnetic beads were drawn to the side of the tubes using a rare earth magnet (Edmund Scientific), and the supernatant removed and saved. The beads were resuspended and washed twice with $100 \mu \mathrm{l}$ of $1 \times \mathrm{SSC} / 1 \%$ Triton $\mathrm{X}-100$. The bound tel omeres were eluted from the beads by melting the oligonucl eotide/ tel omere interaction at $65^{\circ} \mathrm{C}$ for 10 $\min$ in $30 \mu \mathrm{l}$ of $0.1 \times \mathrm{SSC} / 1 \%$ Triton $\mathrm{X}-100$.

The fraction of telomeres recovered [bound $\div$ (bound + unbound)] was quantitated from Phosphorlmager scans of agarose gels probed with labeled (CCCTAA) ${ }_{4}$ oligonucleotide. In some cases, the unbound fraction was subjected to additional cycles of purification. The percent of telomeres recovered during each cycle of binding was normalized to the original amount of input telomeres. For example, if $35 \%$ of the telomeres were recovered during cycle one, then only $65 \%$ of the telomeres would be left as the input to cycle two. A recovery of $20 \%$ of these telomeres would then represent $13 \%(0.2 \times 0.65=0.13)$ of the original telomeres.

Technical points in this protocol include the following consi derations. Forty micrograms of human DN A contains approximately 1 fmole of telomeres, so that 1 pmole oligonucleotide is in vast excess for even rel atively long overhangs. One microliter of magnetic beads can bind at least 1 pmole of biotinylated ol igonucl eotide as measured by its ability to retrieve radioactive $(\text { TTAGGG) })_{4}$ oligonucleotide annealed to the biotinylated CCCTAA oligonucleotides. Although the rate of formation of magnetic bead/small oligonucleotide complexes is very rapid $(1-\mu$ beads can clear 1 pmole of oligonucleotide from $1 \mathrm{ml}$ in $\sim 15 \mathrm{~min}$ ), the rate of binding to the large tel omere/ ol igonucleotide hybrids is very slow. The amount of telomeres bound to 1 pmole of biotinylated oligonucl eotide and $3 \mu$ of beads after an overnight rotation in $30 \mu \mathrm{l}$ was about twice as great as when 1 $\mu \mathrm{l}$ of beads was used, with a minimal increase observed using 10 $\mu \mathrm{l}$ of beads. Three microliters of magnetic beads was used, as larger amounts increased background binding slightly.

\section{Artificial telomeres}

Large DNA fragments with single-stranded G-rich overhangs were constructed by ligating variable numbers of telomeric sequences to a linearized plasmid. Single-stranded ladders of TTAGGG repeats were produced by the asymmetric PCR amplification of a cloned 450-bp telomeric insert using $\left[\alpha{ }^{32} \mathrm{P}\right] \mathrm{dGTP}$ and ddG. The $\sim 100 \mathrm{bp}$ of plasmid sequences between the forward primer and the start of the tel omeric repeats was then made double-stranded, digested with Sall, and ligated to a 5-kbp plasmid digested with Xhol. These enzymes have compatible ends. The resulting artificial telomeres were then gel purified and tested for their ability to bind biotinylated Crich sequences.

\section{Anti-BrdU precipitation of telomeres}

Fibroblasts were grown in $30 \mu \mathrm{M}$ BrdU for $20 \mathrm{hr}$ (less than one doubling) to produce hemisubstituted DN A and for 1 week in 8 $\mu \mathrm{M}$ BrdU to produce DNA labeled in both strands. Deoxycytidine $(200 \mu \mathrm{m})$ was included under both conditions to reduce toxic effects of BrdU. Purified telomeres from $10 \mu \mathrm{g}$ of total genomic DN A were melted at $99^{\circ} \mathrm{C}$ for $3 \mathrm{~min}$, quick chilled, and incubated with $5 \mathrm{ng}$ of anti-BrdU antibody (Becton-Dickinson) for $60 \mathrm{~min}$ at room temperature in $25 \mu \mathrm{l}$ of PBS containing 1\% Triton X-100. Antibody-DNA complexes were then recovered following a 1-hr incubation with $15 \mu$ of protein-G agarose beads (Boehringer $M$ annhei $m$ ) and washed twice for 15 min each in PBS/1\% Triton X-100. The DNA was then eluted from the beads at $99^{\circ} \mathrm{C}$ for $3 \mathrm{~min}$ in TE buffer (10 mM Tris, $1 \mathrm{~mm}$ EDTA at $\mathrm{pH}$ 8) containing $1 \%$ SDS. Input, bound, and unbound fractions were analyzed on duplicate agarose gels probed with either labeled C-rich or G-rich telomeric probes. A pproximately $75 \%$ of the input telomeres were recovered (anti-BrdU bound + unbound) for each strand. The fraction of each strand bound by anti-BrdU antibodies was determined from Phosphorlmager scans of each lane using the formula \% Retrieved $=$ anti - BrdU bound $\div$ (bound + unbound $)\} \times 100$.

\section{Electron microscopy}

Gapped linear DNA (100 ng) or telomeric DN A (140 ng) was incubated with 200 ng of T4 gene 32 protein (Delius et al. 1972; Wu and Davidson 1975) for $5 \mathrm{~min}$ at room temperature in $50 \mu \mathrm{l}$ of $10 \mathrm{~mm}$ HEPES (pH 7.5), $100 \mathrm{mM} \mathrm{NaCl}$, and $2.5 \mathrm{mM} \mathrm{M} \mathrm{gCl}_{2}$. Glutaral dehyde (Sigma) was added to a final concentration of $0.1 \%$ and incubated for $5 \mathrm{~min}$ at room temperature. The crosslinking reaction was quenched by the addition of an equal volume of $10 \mathrm{~mm}$ Tris- $\mathrm{HCl}$ and $1 \mathrm{~mm}$ EDTA. DN A was suspended in a buffer containing $2.5 \mathrm{~mm}$ spermidine and applied to glowdischarged, thin carbon films supported on copper grids (G riffith and Christiansen 1978), rinsed twice in double-distilled water, dehydrated in a graded series of ethanol solutions, briefly stained with $0.1 \mathrm{~mm}$ uranyl acetate in $90 \%$ ethanol, and airdried. Samples were rotary shadowcast at an angle of $7^{\circ}$ using evaporated tungsten wire in a vacuum evaporator cryopumped to $<10^{-6}$ Torr. Size standards were prepared by annealing singlestranded phagemid containing different numbers of telomeric repeats to the complementary strand of the plasmid vector backbone. This hybrid DNA was then restriction digested to produce linear DNA molecules containing known lengths of either internal or terminal regions of single-stranded telomeric repeats.

\section{Terminal restriction fragment analysis}

DNAs isolated from cells at different population doublings throughout their cultured lifespan were digested with a mixture of six restriction enzymes (Alul, Cfol, Haell, Hinfl, Mspl, and Rsal; Rogalla et al. 1994), analyzed on $0.5 \%$ agarose gels, and probed with a label ed (CCCTAA $)_{4}$ probe. Signal intensity is proportional to the number of telomeric repeats using this probe. A verage tel omere length was determined from Phosphorlmager scans after normalizing for this effect using the formula $\Sigma$ (Intensity) $\div \Sigma$ (Intensity $\div$ Length) (Harley et al. 1990).

\section{Acknowledgments}

This work was supported by grants from the $\mathrm{N}$ ational Institutes of Health (NIH) (to W.E.W. and S.D.L), the AlliedSignal corporation (W.E.W. and J.W.S.), and the Welch Foundation (W.E.W.). V.M.T. was funded in part by an NIH Oncology Training Grant. We thank Jennifer Cuthbert for valuable scientific discussions, and Ia Dac-Korytko and M artha Liao for technical support.

The publication costs of this article were defrayed in part by payment of page charges. This article must therefore be hereby marked "advertisement" in accordance with 18 USC section 1734 solely to indicate this fact.

\section{References}

Anderson, S. and M.L. DePamphilis. 1979. Metabolism of Okazaki fragments during Simian Virus 40 DN A replication. J. Biol. Chem. 254: 11495-11504.

Blackburn, E.H. 1994. Telomeres: N o end in sight. Cell 77: 621623. 
Blasco, M.A., W.D. Funk, B. Villeponteau, and C.W. Greider. 1995. Functional characterization and developmental regulation of mouse telomerase RN A. Science 269: 1267-1270.

Cooke, H.J. and B.A. Smith. 1986. Variability at the tel omeres of the human $X / Y$ pseudoautosomal region. Cold Spring Harbor Symp. Quant. Biol. 51: 213-219.

Counter, C.M., A.A. Avillon, C.E. LeFeuvre, N.G. Stewart, C.W. Greider, C.B. Harley, and S. Bacchetti. 1992. Telomere shortening associated with chromosome instability is arrested in immortal cells which express telomerase activity. EMBO J. 11: 1921-1929.

Cross, S.H., R.C. Allshire, S.J. McKay, N.I. McGill, and H.J. Cooke. 1989. Cloning of human telomeres by complementation in yeast. Nature 338: 771-774.

de Lange, T., L. Shiue, R.M. M yers, D.R. Cox, S.L. N aylor, A.M. Killery, and H.E. Varmus. 1990. Structure and variability of human chromosome ends. Mol. Cell. Biol. 10: 518-527.

Delius, H., N.J. M antell, and B. Alberts. 1972. Characterization by electron microscopy of the complex formed between T4 bacteriophage gene 32-protein and DNA. J. Mol. Biol. 67: 341-350.

DePamphilis, M.L. 1993. Eukaryotic DNA replication: A natomy of an origin. Annu. Rev. Biochem. 62: 29-63.

Feng, J., W.D. Funk, S.-S. Wang, S.L. Weinrich, A.A. Avilion, D.-P. Chiu, R.A. Adams, E. Chang, J. Yu, S. Le, M.D. West, C.B. Harley, W.H. Andrews, C.W. Greider, and B. Villeponteau. 1995. The RNA component of human telomerase. Science 269: 1236-1241.

Garvik, G., M. Carson, and L. Hartwell. 1995. Single-stranded DN A arising at telomeres in cdc13 mutants may constitute a specific signal for the RAD9 checkpoint. Mol. Cell. Biol. 15: 6128-6138.

Gottschling, D.E. and T. R. Cech. 1984. Chromatin structure of the molecular ends of Oxytricha macronuclear DNA. Cell 38: 501-510.

Gottschling, D.E. and V.A. Zakian. 1986. Telomere proteins: Specific recognition and protection of the natural termini of Oxytricha macronuclear DNA. Cell 47: 195-205.

Griffith, J.D. and G. Christiansen. 1978. Electron microscope visualization of chromatin and other DNA-protein complexes. Annu. Rev. Biophys. Bioeng. 7: 19-35.

Greider, C.W. 1990. Telomeres, telomerase and senescence. BioEssays 12: 363-369.

- - . 1991. Telomerase is processive. Mol. Cell. Biol. 11: 4572-4580.

- - 1996. Telomere length regulation. Annu. Rev. Biochem. 65: 337-365.

Greider, C.W. and E.H. Blackburn. 1989. A telomeric sequence in the RNA of Tetrahymena telomerase required for telomere repeat synthesis. Nature 337: 331-337.

Harley, C.B. 1991. Telomere loss: Mitotic clock or genetic time bomb? Mutat. Res. 256: 271-282.

Harley, C.B., B.A. Futcher, and C.W. Greider. 1990. Telomeres shorten during ageing of human fibroblasts. Nature 345: 458-460.

Hastie, N.D., M. Dempster, M.G. Dunlop, A.M. Thompson, D.K. Green, and R.C. Allshire. 1990. Telomere reduction in human colorectal carcinoma and with ageing. Nature 346: 866-868.

Henderson, E., D. Larson, W. M elton, J. Shampay, E. Spangler, C. Greider, T. Ryan, and E. Blackburn. 1988. Structure, synthesis and regulation of telomeres. Cancer Cells 6: 453-461.

Klobutcher, L.A., M.T. Swanton, P. Donini, and D.M. Prescott. 1981. All gene-sized DNA molecules in four species of hypotrichs have the same terminal sequence and an unusual $3^{\prime}$ terminus. Proc. Natl. Acad. Sci. 78: 3015-3019.
Levy, M.Z., R.C. Allsopp, A.B. Futcher, C.W. Greider, and C.B. Harley. 1992. Telomere end-replication problem and cell aging. J. Mol. Biol. 225: 951-960.

Lindsey, J., N.I. McGill, L.A. Lindsey, D.K. Green, and H.J. Cooke. 1991. In vivo loss of telomeric repeats with age in humans. Mutat. Res. 256: 45-48.

Lingner, J. and T.R. Cech. 1996. Purification of telomerase from Eupl otes aediculatus: Requirement of a primer 3' overhang. Proc. Natl. Acad. Sci. 93: 10712-10717.

Lingner, J., J.P. Cooper, and T.R. Cech. 1995. Telomerase and DN A end replication: No longer a lagging strand problem? Science 269: 1533-1534.

Lingner, J., T.R. Hughes, A. Shevchenko, M. Mann, V. Lundblad, and T.R. Cech. 1997. Reverse transcriptase motifs in the catalytic subunit of telomerase. Science 276: 561-567.

Liu, Z. and W. Gilbert. 1994. The yeast KEM 1 gene encodes a nuclease specific for G4 tetraplex DNA: Implication of in vivo functions for this novel DNA structure. Cell 77: 10831092.

Makarov, V.L, Y. Hirose, and J.P. Langmore. 1997. Long G tails at both ends of human chromosomes suggest a $\mathrm{C}$ strand degradation mechanism for telomere shortening. Cell 88: 657-666.

McElligott, R. and R.J. Wellinger. 1997. The terminal DNA structure of mammalian chromosomes. EMBO J. 16: 37053714.

Moyzis, R.K., J.M. Buckingham, L.S. Cram, M. Dani, L.L. Daven, M.D. Jones, J. M eyne, R.L. Ratliff, and J.-R. Wu. 1988. A highly conserved repetitive DN A sequence, (TTAGGG)n, present at the telomeres of human chromosomes. Proc. N atl. Acad. Sci. 85: 6622-6626.

Nugent, C.I., T.R. Hughes, N.F. Lue, and V. Lundblad. 1996. Cdc13: A single-strand telomeric DN A-binding protein with a dual role in yeast tel omere maintenance. Science 274: 249252.

Olovnikov, A.M. 1973. A theory of marginotomy. J. Theor. Biol. 41: 181-190.

Prowse, K.R. and C.W. Greider. 1995. Developmental and tissue specific regulation of mouse tel omerase and tel omere length. Proc. Natl. Acad. Sci. 92: 4818-4822.

Raghuraman, M.K., J.B. Bonita, and W.L. Fangman. 1997. Cell cycle-dependent establishment of a late replication program. Science 276: 806-809.

Rogalla, P., B. Kasmierczak, C. Rohen, G. Trams, S. Bartnitzkle, and J. Bullerdiek. 1994. Two human breast cancer cell lines showing decreasing telomeric repeat length during early in vitro passaging. Cancer Genet. Cytogenet. 77: 19-25.

Roth, M. and D.M. Prescott. 1985. DN A intermediates and telomere addition during genome reorganization in Euplotes crassus. Cell 41: 411-417.

Shay, J.W. and S. Bacchetti. 1997. A survey of telomerase activity in human cancer. Eur. J. Cancer 33: 787-791.

Shay, J.W., W.E. Wright, D. Brasiskyte, and B.A. Van der Haegen. 1993. E6 of human papillomavirus type 16 can overcome the M 1 stage of immortalization in human mammary epithelial cells but not in human fibroblasts. Oncogene 8: 1407-1413.

Shay, J.W., D. Brasiskyte, M. Ouellette, M.A. Piatyszek, H. Werbin, Y. Ying, and W.E. Wright. 1994. Analysis of telomerase and telomeres. In Methods in Molecular Genetics (ed. K.W. Adolph), Vol. 5, pp. 263-280. Academic Press, New York, NY.

Shippen-Lentz, D. and E.H. Blackburn. 1989. Telomere terminal transferase activity from Euplotes crassus adds large numbers of TTTTGGGG repeats onto telomeric primers. Mol. Cell. Biol. 9: 2761-2764. 
Singer, M.S. and D.E. Gottschling. 1994. TLC1: Template RN A component of Saccharomyces cerivisiae tel omerase. Science 266: 404-409.

Vaziri, H., F. Schachter, I. Uchida, L. Wei, X. Zhu, R. Effros, D. Cohen, and C.B. Harley. 1993. Loss of telomeric DN A during aging of normal and trisomy 21 human lymphocytes. Am. J. Hum. Genet. 52: 661-667.

Vermeesch, J.R. and C.M. Price. 1994. Telomeric DNA sequence and structure following de novo telomere synthesis in Euplotes crassus. Mol. Cell. Biol. 14: 554-566.

von Zglinicki, T., G. Saretzski, W. Döcke, and C. Lotze. 1995. Mild hyperoxia shortens tel omeres and inhibits prol iferation of fibroblasts: a model for senescence? Exp. Cell Res. 220: 186-193.

Watson, J.D. 1972. Origin of concatameric T4 DNA. Nature 239: 197-201.

Waga, S. and B. Stillman. 1994. Anatomy of a DNA replication fork revealed by reconstitution of SV40 DN A replication in vitro. Nature 369: 207-212.

Wellinger, R.J., A.J. Wolf, and V.A. Zakian. 1993. Saccharomyces telomeres acquire single-strand $\mathrm{TG}_{1-3}$ tails late in $\mathrm{S}$ phase. Cell 72: 51-60.

Wellinger, R.J., K. Ethier, P. Labrecque, and V.A. Zakian. 1996. Evidence for a new step in telomere maintenance. Cell 85: 423-433.

Wright, W.E. and J.W. Shay. 1995. Time, telomeres and tumours; is cellular senescence more than an anticancer mechanism? Trends Cell Biol. 5: 293-296.

Wright, W.E., M.A. Piatyszek, W.E. Rainey, W. Byrd, and J.W. Shay. 1996. Telomerase activity in human germline and embryonic tissues and cells. Dev. Genet. 18: 173-179.

Wu, M. and N . Davidson. 1975. U se of gene 32-protein staining of single-strand polynucleotides for gene mapping by electron microscopy: application to the $\pi 80 \mathrm{~d}_{3} \mathrm{ilvsu}^{+} 7$ system. Proc. Natl. Acad. Sci. 72: 4506-4510.

Zahler, A.M. and D.M. Prescott. 1988. Telomere terminal transferase activity in the hypotrichous ciliate Oxytricha nova and a model for replication of the ends of linear DNA molecules. Nucleic Acids Res. 16: 6953-6972.

Zakian, V.A. 1995. Tel omeres: Beginning to understand the end. Science 270: 1601-1607. 


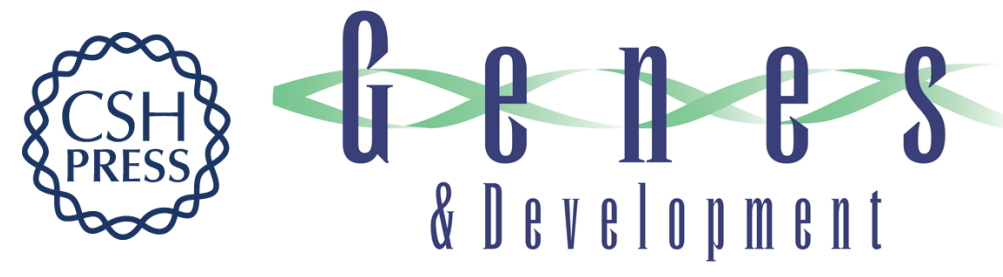

\section{Normal human chromosomes have long G-rich telomeric overhangs at one end}

Woodring E. Wright, Valerie M. Tesmer, Kenneth E. Huffman, et al.

Genes Dev. 1997, 11:

Access the most recent version at doi:10.1101/gad.11.21.2801

References This article cites 50 articles, 20 of which can be accessed free at: http://genesdev.cshlp.org/content/11/21/2801.full.html\#ref-list-1

License

Email Alerting Receive free email alerts when new articles cite this article - sign up in the box at the top Service right corner of the article or click here.

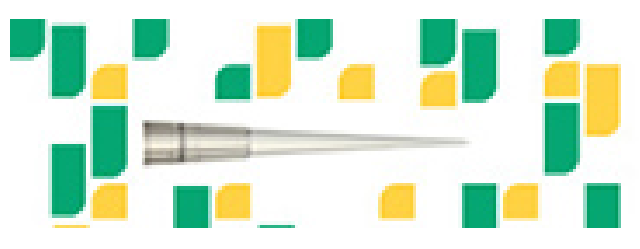

Focused on your science. 